\title{
Outcome of community-based rehabilitation program for people with mental illness who are considered difficult to treat
}

\author{
Angelo Barbato, MD; ${ }^{1 *}$ Germana Agnetti, MD; ${ }^{2}$ Barbara D’Avanzo, DPhil; ${ }^{1}$ Maria Frova, MD; ${ }^{2}$ Antonino \\ Guerrini, MD; ${ }^{2}$ Mauro Tettamanti, ScD $^{1}$ \\ ${ }^{1}$ Mario Negri Institute for Pharmacological Research, Milan, Italy; ${ }^{2}$ Department of Mental Health, Azienda Ospedaliera \\ Niguarda Cà Granda, Milan, Italy
}

\begin{abstract}
This observational study investigated the outcomes of a community-based rehabilitation program that was designed to enhance social functioning, social inclusion, and well-being of people with mental illness who were considered treatment failures by psychiatric professionals in Italy. Of the 144 patients who entered the program, 131 started the program and 109 completed either 12 or 18 months of treatment. Illness severity was assessed by the Health of the Nation Outcome Scales (HoNOS) and social functioning by the Social and Occupational Functioning Assessment Scale (SOFAS). On the HoNOS, $33 \%$ of patients showed reliable change. On the SOFAS, $27 \%$ showed reliable change, although the change was substantial for few patients. Over time, patients showed moderate but significant improvements on the HoNOS and SOFAS. The HoNOS subscales concerning interpersonal relationships and social inclusion showed significant change. Very isolated people with mental illness gained some advantages from this rehabilitation program that was based on a close relationship with a key worker; however, the program duration may have been inadequate to produce substantial changes. Our findings warrant further research based on controlled studies.
\end{abstract}

Key words: assertive outreach, case management, clinical outcome, community mental health services, functional outcome, Italy, outcome study, psychiatric rehabilitation, psychosis, severe mental illness.

\section{INTRODUCTION}

As a result of substantial changes in the mental health system, the majority of people in Italy with severe mental illness spend most of their life in the community rather than large isolated institutions [1]. Therefore their treatment needs, including psychiatric rehabilitation, must be met by community-based services. However, for a variety of reasons, a small but significant subgroup of people with enduring mental illness are not successfully engaged by mainstream services and are at greater risk of repeated hospital admissions, isolation, and social exclusion. These socalled "difficult patients" are a well-known reality of mental health services in all Western countries [2]. Although earlier studies focused on the patient characteristics that contributed to active refusal of, avoidance of, or poor response to treatment [3], in recent years the role of service features and staff working style-attitude in treatment resistance has been increasingly recognized [4]. This recognition has led to the development of specific service models that address the challenges posed by people with multiple and long-term needs who do not respond well to traditional

\footnotetext{
Abbreviations: ACT $=$ assertive community treatment, HoNOS $=$ Health of the Nation Outcome Scales, ICD-10 = International Classification of Diseases-10th Edition, SD = standard deviation, SOFAS = Social and Occupational Functioning Assessment Scale, UP = Urban Project.

*Address all correspondence to Angelo Barbato, MD; Epidemiology and Social Psychiatry Unit, Mario Negri Institute for Pharmacological Research, Via La Masa 19, 20156 Milan, Italy; +39-02-39014431; fax: +39-02-39014300.

Email: barbato@marionegri.it

DOI: 10.1682/JRRD.2007.02.0041
} 
mental health services and are considered "treatment failures" by providers. Such models usually fall into two broad categories: case management and assertive community treatment (ACT). Although the differences are not necessarily clear-cut, case management is based on autonomy and the individual responsibility of a single professional to his or her patients [5], while ACT emphasizes a team approach that merges clinical and rehabilitation components within one mobile service-delivery system [6]. In the United States, where it was developed as an alternative to psychiatric hospitalization, ACT is considered an evidencebased approach [6]. However, its replication across the Atlantic led to disappointing results, raising doubts about its applicability in Western Europe, including Italy, without substantial modifications [7-8]. Moreover, a close examination of ACT modes of operation and the users' experiences highlight two problems: first, most interventions do not have a rehabilitation focus [9] and second, some users perceive ACT as an intrusive form of control [10].

On the basis of these considerations, the Urban Project (UP) was designed and implemented to address the needs of severely disabled patients with mental illness who did not receive adequate care from the community mental health services of the city of Milan. The UP was designed to include aspects of successful service models from international research, while accounting for specific aspects of the Italian context. The description and evaluation of the UP are the subject of this article.

\section{METHODS}

\section{Setting}

The UP involved all mental health services in Milan, the second largest city in Italy with a population of 1.3 million. Mental health services in Milan are community-based and fully equipped with multidisciplinary teams and a wide range of facilities, including hospital inpatient units for acute care, residential facilities, day care centers, and community mental health teams. No mental hospital beds are available because all mental hospitals in Italy were closed between 1980 and 2000. Milan services are grouped into six Departments of Mental Health, which are attached to general hospitals and provide mental health services to well-defined geographical areas. Overall, 147 acute psychiatric beds (1.34 per 10,000 adults) are available and 18 district-based community mental health teams serve, on average, an adult population of 61,000 each. The caseload of Milan mental health services in 2001 was 15,184 patients, of which 24 percent had a diagnosis of schizophrenia and related disorders [11]. All departments provide a mix of rehabilitation programs for the most severely ill patients. We should note that despite the services' community orientation, in 2001 only 20 percent of patient contacts occurred outside the clinics.

\section{Project Description and Rationale}

The UP was an outreach pilot program of limited duration that was specifically designed to provide intensive psychosocial rehabilitation for 12-18 months to difficultto-treat patients with severe mental illness. The UP was in some aspects similar to a time-limited ACT but in others was closer to a case management program. The project was not intended as an alternative to mainstream psychiatric services, and community mental health teams continued to be completely in charge of drug treatment, hospitalization, residential services, and day care (if necessary). Moreover, the patients had to be referred back to mainstream services at the end of the program, which lasted at least 12 and no more than 18 months, depending on the patients' needs.

In 2003, Milan community mental health teams were asked to refer to the UP patients who satisfied the following criteria:

1. Aged 18 to 50 years.

2. International Classification of Diseases-10th Edition (ICD-10) diagnosis of any mental illness, excluding organic mental illness (codes F0-F09), substance use disorders (codes F10-19), and mental retardation (codes F70-F79) [12].

3. Low level of social functioning, as indicated by a Social and Occupational Functioning Assessment Scale (SOFAS) score of $\leq 50$ [13].

4. Treatment failure label because of repeated engagement problems, failure to attend rehabilitation programs, or lack of improvement despite compliance with treatment.

No attempt was made to set operational criteria for the definition of treatment failure because it is a label given by clinicians; therefore, the community mental health teams were free to consider their patients treatment failures according to their own evaluation.

The project team consisted of the following:

1. Core group.

2. Community mental health team liaison group.

3. Evaluation group. 
The core group comprised 45 key employees working $20 \mathrm{~h} /$ wk, 5 clinical psychologists providing supervision $10 \mathrm{~h} / \mathrm{wk}$, the half-time project manager, and the scientific director.

Most key workers had a master's degree in psychology, occupational therapy, or education. They received, on average, $3 \mathrm{~h} / \mathrm{wk}$ of group supervision, which also provided a sort of mutual emotional support. Key workers were selected according to their "soft approach" characteristics: relationship-building skills; recent graduation; outlook not yet influenced by mental health service mentality; and ability to keep a lay attitude, while tenaciously pursuing rehabilitation and clinical goals. In practical terms, they worked alone with the patient, without any sort of mediation by the service team. Their caseload ratio was 1:3, and they had no fixed work hours or workplace.

The five clinical supervisors supervised an average of nine key workers for at least $3 \mathrm{~h} / \mathrm{wk}$, allowing them to vent feelings and work through their emotional involvement with patients in addition to discussing cases and projects. They also met regularly with the community mental health teams before the start of the project to select the patients and subsequently to discuss patients' needs and formulate rehabilitation plans.

The community mental health team liaison group comprised two liaison professionals who worked a few hours a week in collaboration with the project team: the liaison professionals kept in regular contact with the UP patients referred from his or her team, kept track of them, and assessed their conditions. The treating psychiatrist on the community mental health team continued to manage drug treatment and provided access to hospital or residential care.

The evaluation group consisted of two people for data collection and data quality check, one for data input, one for data management and analysis, and two for cost analysis (which will be presented in a subsequent article).

Other resources were a small budget of 50 euros (\$65) a month for each patient, which was meant to broaden access to community events and facilities, and a "community resource map," which was tailored to facilitate engagement in ordinary community activities.

Key goals of the UP were the enhancement of patients' social functioning, general well-being, and social inclusion through participation in community life. Specific issues such as self-care, psychological wellbeing, family relationships, and interpersonal skills were addressed as intermediate goals. The UP was conducted in three phases: engagement, rehabilitation program implementation, and closure.
In the engagement phase, flexible individualized strategies were used: key workers were more likely to comply with patients' wishes than pursue a rigid professional agenda. The main rehabilitation tool was the establishment of a strong relationship based on trust and alliance, where assertive strategies were replaced by soft strategies based on patience and continuity.

Key workers met their patients regularly in different contexts and at different times of the day or night. They did not have a specific place for their activities, and they were keen to meet patients' needs and wishes with a contractual approach. This was a major feature of the program and was linked to the idea that for noncompliant patients, lowering professional power was very important. Having no fixed workplace made using community resources natural and easier. The key worker easily became a key person for patients' families, and family members were engaged first individually and as soon as possible thereafter in self-help groups.

When trust and alliance with the patient were established, the key worker became very much like a tutor. Within this relationship, rehabilitation goals were set up naturally, although some pressure was almost unavoidable.

In the rehabilitation phase, goals were identified and pursued through the use of Skills Assessment and Objective Planning, a tool for both intervention and evaluation [13]. Most of the rehabilitation work was done individually but group meetings also became important. A further step was identifying specific groups in the community, such as soccer teams, theater companies, or music bands that could help patients participate in social interactions and meaningful activities.

In the closure phase, follow-up assessment was completed, patient's changes were reviewed with the patient, and plans were made between the UP key worker, the community mental health team, and the patient regarding the referral back to mainstream services.

\section{Measures}

This study was conceived as a naturalistic longitudinal study, where changes in values on various scales were used as outcome indicators. Evaluations were scheduled after 6 and 12 months for all patients. An additional 18-month evaluation was scheduled for patients who remained in the program for the longest period allowed. The study was approved by the ethics review board of the Azienda Ospedaliera Niguarda Cà Granda (Niguarda Cà Granda Hospital Trust) of Milan. 
Sociodemographic information, ICD-10 psychiatric diagnosis, and other clinical characteristics of the patients were collected through a recruitment form. Illness severity was evaluated with the Italian version of the multidimensional Health of the Nation Outcome Scales (HoNOS) [14], which is a clinician-rated instrument comprising 12, fivepoint scales that range from 0 (no problem) to 4 (very severe problem) and cover both clinical and psychosocial areas. Social functioning was evaluated with the modified Italian version of the SOFAS, which is included in the American Psychiatric Association multiaxial classification system for assessing an individual's functional level independently from the overall severity of psychiatric symptoms. It is an ordinal scale with scores that range from 1 (extremely low functioning) to 100 (superior functioning) [13]. The HoNOS was completed by the treating psychiatrist of the community mental health team and the SOFAS by the liaison professional. All clinicians attended specific training sessions for the administration of both scales.

Quality of life was evaluated with the Italian version of the Lancashire Quality of Life Profile [15] and family burden by the Family Problem Questionnaire [16]. Meaningful life events were recorded on the Event Monitoring Form every 6 months, and at 18 months, an ad hoc questionnaire on satisfaction with the treatment was selfadministered by patients and family members.

Service use, i.e., number of contacts with the community mental health teams, number of voluntary and compulsory admissions to acute inpatient units with total length of stay, and number of admissions to residential facilities with total length of stay, were retrieved from the Lombardy Region Mental Health Information System [11] for the 18 months before and the 18 months following the start of the study.

\section{Subjects}

Between January and September 2003, a total of 200 patients were referred to the UP by the Milan community mental health teams: 28 (14\%) did not satisfy the inclusion criteria and 28 (14\%) refused to participate in the program. A total of 144 patients entered the project. However, 13 (9\%) dropped out very early in the study. These subjects did not complete the full baseline assessment and were not included in the analysis. Therefore, the study sample comprised 131 subjects, whose sociodemographic and clinical characteristics are shown in Table 1.

Of the 131 patients in the study sample, 109 (83\%) completed the 12- to 18-month treatment program, 18 (14\%) dropped out before 6 months, and 4 (3\%) dropped
Table 1.

Distribution of sociodemographic and clinical characteristics of study sample $(n=131)$.

\begin{tabular}{|c|c|}
\hline Characteristic & $n(\%)$ \\
\hline \multicolumn{2}{|l|}{$\begin{array}{l}\text { Sex } \\
\text { n }\end{array}$} \\
\hline Male & $86(66)$ \\
\hline Female & $45(34)$ \\
\hline \multicolumn{2}{|l|}{ Age $(y r)($ mean \pm SD $=38.0 \pm 8.7)$} \\
\hline$<30$ & $23(18)$ \\
\hline 30-39 & $49(37)$ \\
\hline $40-49$ & $50(38)$ \\
\hline$\geq 50$ & $9(7)$ \\
\hline \multicolumn{2}{|l|}{ Marital Status } \\
\hline Single & $105(80)$ \\
\hline Ever Married & $26(20)$ \\
\hline \multicolumn{2}{|l|}{ Living Arrangement } \\
\hline Alone at Own Home & $22(17)$ \\
\hline With Parents & $81(62)$ \\
\hline With Partner & $13(10)$ \\
\hline Homeless & $3(2)$ \\
\hline Sheltered Residence & $3(2)$ \\
\hline Unknown & $9(7)$ \\
\hline \multicolumn{2}{|l|}{ Education (yr) } \\
\hline$\leq 8$ & $79(60)$ \\
\hline$>8$ & $43(33)$ \\
\hline Unknown & $9(7)$ \\
\hline \multicolumn{2}{|l|}{ Employment } \\
\hline Unemployed & $116(88)$ \\
\hline Employed & $10(8)$ \\
\hline Housewife & $5(4)$ \\
\hline \multicolumn{2}{|l|}{ Diagnosis } \\
\hline Schizophrenic Disorder & $97(74)$ \\
\hline Personality Disorder & $13(10)$ \\
\hline Affective Disorder & $4(3)$ \\
\hline Other & $17(13)$ \\
\hline \multicolumn{2}{|l|}{$\begin{array}{l}\text { Age 1st Mental Health Service Contact (yr) } \\
(\text { mean } \pm \text { SD }=24.2 \pm 11.8)\end{array}$} \\
\hline$<20$ & $31(24)$ \\
\hline $20-29$ & $63(48)$ \\
\hline$\geq 30$ & $33(25)$ \\
\hline Unknown & $4(3)$ \\
\hline \multicolumn{2}{|l|}{ Hospital Admission Last Year } \\
\hline None & $73(56)$ \\
\hline$\geq 1$ & $47(36)$ \\
\hline Unknown & $11(8)$ \\
\hline \multicolumn{2}{|l|}{ Antipsychotic Medication Last Year } \\
\hline Typical & $46(35)$ \\
\hline Atypical & $46(35)$ \\
\hline Typical and Atypical & $16(12)$ \\
\hline None & $23(18)$ \\
\hline \multicolumn{2}{|l|}{ Illness Severity (HoNOS) } \\
\hline Very Severe (severe problems in $\geq 2$ subscales) & $108(82)$ \\
\hline Severe & $13(10)$ \\
\hline Mild & $10(8)$ \\
\hline \multicolumn{2}{|c|}{ Functioning Level (SOFAS) (mean \pm SD $=31.1 \pm 9.2)$} \\
\hline Very Low $(<31)$ & $61(47)$ \\
\hline $31-50$ & $66(50)$ \\
\hline$\geq 51$ & $2(2)$ \\
\hline Unknown & $2(2)$ \\
\hline $\begin{array}{l}\text { HoNOS = Health of the Nation Outcome Scale } \\
\text { SOFAS = Social and Occupational Functioning A }\end{array}$ & $\begin{array}{l}\text { andard d } \\
\text { Scale. }\end{array}$ \\
\hline
\end{tabular}


out between 6 and 12 months. We found no significant differences between the subjects who did and who did not complete the program.

\section{Data Collection and Analysis}

After 6 months, 113 subjects (86\% of the study sample) completed the HoNOS and 109 (83\% of the study sample) completed the SOFAS. At end of the program (12 or 18 months), 103 of the patients (95\% of those who completed the program) completed the HoNOS and all 109 of those who completed the program completed the SOFAS.

Illness severity (assessed with the HoNOS) was defined as suggested by Lelliott [17] as the number of subscales on which subjects scored a 3 or 4 . A subject was considered severely ill if he or she had a score of 4 on $\geq 1$ or a score of 3 on $\geq 2$ HoNOS subscales, excluding subscale 5 (physical illness or disability).

We conducted a categorical analysis on the HoNOS total score modifications using the criteria for reliable and clinically significant change [18]. According to these criteria, a change on the HoNOS total score was reliably detected when it was $\geq 7$ points. In addition, a change was considered clinically meaningful when a subject crossed the threshold between two illness severity levels. The cutoff point that distinguished very severe from severe mental illness was 12 and severe from mild was 7 . Therefore, in this analysis, reliable worsening for the HoNOS was an increase of $\geq 7$ points, and reliable improvement was a decrease of $\geq 7$ points. Moreover, since this population showed very severe levels of mental illness at baseline, 12 was considered the cutoff point for clinically significant change. The score on subscale 12, "Occupation and Activity Problems," was considered a proxy measure of social inclusion.

Similar assumptions were made for the SOFAS: the reliable change was a variation of 10 points, and we assumed 51 as the cutoff point to distinguish between serious $(<51)$ and moderate $(\geq 51)$ impairment in social/ occupational functioning [18].

In the follow-up analysis, we considered together all subjects with available data at the end of the program
(12 or 18 months). For patients with data at both 12- and 18-month follow-up, we used data from the last assessment. We therefore analyzed data for reliable and clinically significant change in 103 subjects on the HoNOS and 109 subjects on the SOFAS.

We used the McNemar test of marginal homogeneity to evaluate from the single items on the HoNOS whether the proportion of patients rated as severe or very severe at follow-up was significantly different from the proportion of patients rated severe or very severe at baseline.

Moreover, we assessed the change over time on both the HoNOS and SOFAS by comparing the mean scores at baseline, 6, 12, and 18 months. As the longitudinal evolution of the HoNOS and SOFAS was not anticipated to follow a specific pattern, we used a profile analysis that let the estimates of the mean vary in an arbitrary way [19]. Analyses were performed with SAS, version 8.2, (SAS Institute Inc, Cary, North Carolina); we used the mixed procedure to account for all available data.

\section{RESULTS}

Most subjects were single adult males living with their parents, with low education, a diagnosis of schizophrenic disorder, and a long history of mental illness, and almost all were unemployed. A small number of subjects aged $\geq 50$ yr entered the program despite the age inclusion criteria. The HoNOS and SOFAS data showed severe psychopathology and very low social functioning. However, very few subjects were homeless or living in sheltered residences. Moreover, their compliance with the medical treatment was to some extent adequate, as indicated by the high percentage of patients taking medication. Only 10 percent of patients with a diagnosis of schizophrenic disorder were not on antipsychotic medication at baseline.

Reliable and clinically significant changes in the HoNOS and SOFAS total score are presented in Table 2.

Table 2.

Change on Health of the Nation Outcome Scales (HoNOS) $(n=103)$ and Social and Occupational Functioning Assessment Scale (SOFAS) $(n=109)$ at either 12- or 18-month follow-up. Data presented as $n(\%)$.

\begin{tabular}{ccccc}
\hline Outcome Measure & Worsening & No Change & Improvement & $\begin{array}{c}\text { Clinically Significant } \\
\text { Improvement }\end{array}$ \\
\hline HoNOS & $2(2)$ & $67(65)$ & $14(14)$ & $20(19)$ \\
SOFAS & $6(6)$ & $73(67)$ & $21(19)$ & $9(8)$ \\
\hline \hline
\end{tabular}


One-third of the patients improved on the HoNOS, although the improvement was considered clinically significant for only one-fifth. The changes on the SOFAS were smaller, with only a very small number of patients exhibiting clinically significant improvement.

At baseline, 82 percent of the subjects were very severely ill according to the HoNOS; at follow-up, 56 percent were very severely ill $(p<0.001)$. The percentage of subjects with severe or very severe illness decreased significantly on the four HoNOS subscales that had the highest numbers of patients with severe illness at baseline. These subscales were nonspecific psychiatric symptoms, relationship problems, activities of daily living, and occupation and activity problems (Table 3).

Significant changes on both assessments, and particularly on the HoNOS, were noted at 6, 12, and 18 months (Figure). The larger error values on the SOFAS suggest a wider range of patient scores. Most of the change occurred within the first 6 months followed by a plateau in the next 6 months and then a smaller amount of improvement in the final 6 months. We should note that the improvement, although statistically significant, was moderate in size. The mean \pm standard deviation (SD) HoNOS scores of those who completed the program changed from $19.5 \pm 6.6$ to $14.9 \pm 6.8$, and the mean \pm SD SOFAS scores of those who completed the program changed from $31.1 \pm 9.2$ to $37.2 \pm$ 10.8. Most patients, although improved, remained severely disabled at the end of the program.

\section{DISCUSSION}

First and foremost, we have to note that observational studies carried out in naturalistic settings are very challenging. Obviously, the lack of a control group and the nonblinded patient assessments limit the validity of the results. However, our findings are of interest because ours is one of the few studies that investigated the realworld implementation of a specialized rehabilitation program for people with difficult-to-treat mental illness outside Anglo-Saxon countries.

Closely examining the study population characteristics highlights that the community mental health teams referred patients with severe enduring psychiatric (mostly psychotic) symptoms, characterized by poor interpersonal relationships and social isolation, to the UP. However, the patients lacked some of the distinctive features of their American counterparts usually considered suitable for ACT [6]. They lived with their families and very few were homeless, they did not have a history of repeated hospital admissions, and they were at least partially engaged in care, as indicated by the high percentage of patients taking antipsychotic drugs. Such features are to some extent related to aspects of the Italian context: first, the strength of family ties in Italy, even for people with severe disability, has been already noted [20] and second, after the men-

Table 3.

Subjects with severe or very severe problems in 12 Health of the Nation Outcome Scales (HoNOS) subscales at baseline ( $n=131)$ and either 12 or 18-month $(n=103)$ follow-up. Data presented as $n(\%)$.

\begin{tabular}{|c|c|c|}
\hline HoNOS Subscale & Baseline & Follow-Up \\
\hline Aggression & $16(16)$ & $12(12)$ \\
\hline Self-Harm & $3(3)$ & - \\
\hline Cognitive Problems & $18(17)$ & $15(15)$ \\
\hline Physical Illness/Disability & $10(10)$ & $7(7)$ \\
\hline Nonspecific Psychiatric Symptoms* & $50(49)$ & $32(31)$ \\
\hline Relationship Problems ${ }^{\dagger}$ & $73(71)$ & $47(46)$ \\
\hline Activities of Daily Living* & $57(55)$ & $38(37)$ \\
\hline Living Conditions & 30 (29) & $22(21)$ \\
\hline
\end{tabular}




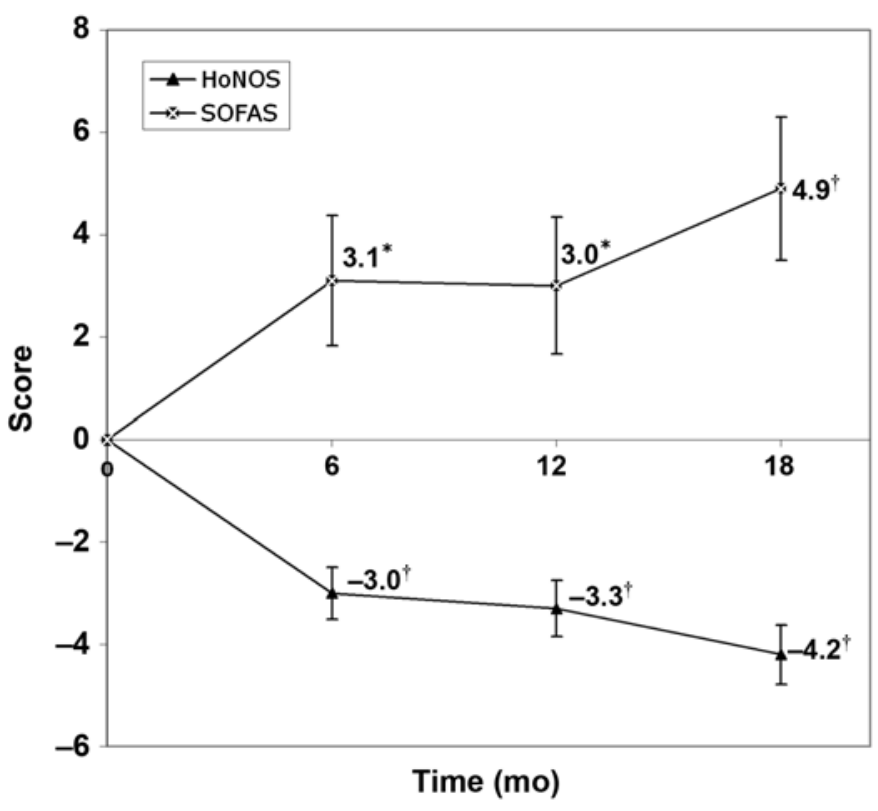

Figure.

Illness severity assessed by Health of the Nation Outcome Scales (HoNOS) and social functioning by Social and Occupational Functioning Assessment Scale (SOFAS) at baseline, 6, 12, and 18 months. Error bars represent standard error of the mean. ${ }^{*} p<0.05,{ }^{\dagger} p<0.001$.

tal hospitals closed, access to inpatient care in Italy has been restricted, and the availability of acute psychiatric beds is very low [21]. However, community mental health teams clearly labeled well-known patients as treatment failures because they had long-standing problems and did not respond well to routine care, despite compliance with drug treatment. The community mental health teams probably felt they lacked both resources and hope to engage socially isolated patients in intensive rehabilitation. Last, the exclusion from the project of patients with comorbid substance abuse explains the low numbers of patients who exhibited aggressive behavior or suicide risk.

The UP was moderately successful in engaging the patients. More than one-third of referred patients who satisfied the inclusion criteria refused or dropped out from the program. However, almost all patients who completed the engagement phase remained in the program. Patients' improvement in overall social functioning was not impressive. However, the most improved areas were interpersonal skills, link with the social network, and participation in the community. General psychological well-being improved in many patients, despite the persistence of psychotic symptoms. Such results were the goals of the method and intervention: the main focus was the patient-key worker relationship, through which social inclusion was enhanced. The community participation mainly involved access to recreational and leisure activities, which, according to recent suggestions, possess a number of characteristics that make them useful for facilitating the social inclusion of persons with disabilities. Some characteristics of these settings encourage the development of skills and attitudes-beliefs that promote the enhancement of social relationships [22].

Patients might have improved simply because, given their very severe conditions, they had more room for improvement. This explanation would be an example of the well-known regression to the mean phenomenon. Although a naturalistic design cannot completely rule out this explanation, this effect is mainly seen in short-term observations of acute problems or in long-term conditions when a continuous variable is measured in two assessments [23]. Since we performed multiple assessments over time, the changes observed were not likely caused by a regression to the mean.

The number of subjects who dropped out became a problem. Nonetheless, the results were not affected by exclusion of subjects who worsened because the profile analysis included those who dropped out.

The examination of ACT studies in Europe suggests further considerations. A Swiss study on a time-limited ACT for difficult to engage patients found results similar to ours, although the use of different outcome measures makes a full comparison difficult [24]. Moreover, the Swiss sample included many patients with substance abuse who exhibited aggressive behavior.

An English study investigated the processes that might cause patients who were previously disengaged from services to engage with assertive outreach teams [25]. Several key elements of the treatment program and the key workers seemed related to engagement after a period of disengagement: more available time, more commitment to the care of each person, creation of mutually trusting relationships, consistency over longer periods, less focus on medication and compliance, and assistance with practical everyday issues. Another key element of engagement was the subjects having a genuine say in decisions involving their own care. The reasons they found for disengagement were the same as those seen in patients' previous experiences with mainstream services $[10,20]$, which suggests that different approaches may 
influence patients' engagement. The findings of our study seem consistent with such indications.

Last but not least, in the UP, a critical factor was the program duration. The UP was designed with a time limitation, but the results from the last 6 months, as shown in the Figure, suggest that most patients needed a longer program. Actually, anecdotal information collected from a number of patients at the end of study showed that, for a variety of reasons, patients were still followed by the UP and the referral back to mainstream services did not occur. These reasons included patients' and families' opposition to reduction or cessation of interventions, patients' and UP professionals' difficulties with discharge or separation, and mainstream services' difficulties with creating an alliance with patients.

\section{CONCLUSIONS}

In summary, we found that very isolated people with mental illness who had overwhelming difficulties with interpersonal relationships gained some advantages from this rehabilitation program that was based on a close relationship with a committed key worker; however, the program duration may have been inadequate to produce relevant change. Although improvements were significant and greater than normally expected with standard care, the observational study design prevents us from drawing firm conclusions about the effectiveness of the intervention.

What are the elements that explain the effects of the UP? This intervention was strongly characterized by a relationship between two people- the patient and the key worker-as a means of pursuing social inclusion, and by individual strategies, communication styles, and goals. The care intensity was flexible and varied according to the different subjects, but continuity of care was guaranteed even when contacts were infrequent. Commitment and motivation of the key workers were very strong.

Although these elements warrant further research based on controlled studies, we believe they should be integrated into mainstream Italian mental health services and ordinary care. However, identification of patients who may benefit from such an approach is a key issue that requires more investigation.

\section{ACKNOWLEDGMENTS}

This material was based on work supported by the Ministry of Health, Italian Republic, Project 71, Law 448/98, Ministry Ordinance, September 5, 1999, "Reorganization and quality improvement of healthcare in the city of Milan"; Subproject 5, "Interventions for mental health in the city of Milan."

The authors have declared that no competing interests exist.

\section{REFERENCES}

1. Barbato A. Psychiatry in transition: Outcomes of mental health policy shift in Italy. Aust N Z J Psychiatry. 1998; 32(5):673-79. [PMID: 9805590]

2. Koekkoek B, Van Meijel B, Hutschemaekers G. "Difficult patients" in mental health care: A review. Psychiatr Serv. 2006;57(6):795-802. [PMID: 16754755]

3. Neill JR. The difficult patient: Identification and response. J Clin Psychiatry. 1979;40(5):209-12. [PMID: 438141]

4. Priebe S, Fakhoury W, White I, Watts J, Bebbington P, Billings J, Burns T, Johnson S, Muijen M, Ryrie I, Wright C, Pan-London Assertive Outreach Study Group. Characteristics of teams, staff and patients: Associations with outcomes of patients in assertive outreach. Br J Psychiatry. 2004;185:306-11. [PMID: 15458990$]$

5. Solomon P, Draine J, Delaney MA. The working alliance and consumer case management. J Ment Health Adm. 1995;22(2):126-34. [PMID: 10142126]

6. Phillips SD, Burns BJ, Edgar ER, Mueser KT, Linkins KW, Rosenheck RA, Drake RE, McDonel Herr EC. Moving assertive community treatment into standard practice. Psychiatr Serv. 2001;52(6):771-79. [PMID: 11376224]

7. Burns T, Fioritti A, Holloway F, Malm U, Rössler W. Case management and assertive community treatment in Europe. Psychiatr Serv. 2001;52(5):631-36. [PMID: 11331797]

8. Killaspy H, Bebbington P, Blizard R, Johnson S, Nolan F, Pilling S, King M. The REACT study: Randomised evaluation of assertive community treatment in north London. BMJ. 2006;332(7545):815-20. [PMID: 16543298]

9. Wright C, Burns T, James P, Billings J, Johnson S, Muijen M, Priebe S, Ryrie I, Watts J, White I. Assertive outreach teams in London: Models of operation. Pan-London Assertive Outreach Study, part 1. Br J Psychiatry. 2003;183: 132-38. [PMID: 12893666]

10. Watts J, Priebe S. A phenomenological account of users' experience of assertive community treatment. Bioethics. 2002;16(5):439-54. [PMID: 12472092] 
11. Gandini AM, Lora A. L'attività delle Unità Operative di Psichiatria 2001. Milan (Italy): Regione Lombardia Sanità; 2003.

12. World Health Organization (WHO). The ICD-10 classification of mental and behavioral disorders: Diagnostic criteria for research. Geneva (Switzerland): WHO; 1993.

13. Morosini PL, Magliano L, Brambilla L, Ugolini S, Pioli R. Development, reliability and acceptability of a new version of the DSM-IV Social and Occupational Functioning Assessment Scale (SOFAS) to assess routine social functioning. Acta Psychiatr Scand. 2000;101(4):323-29. [PMID: 10782554

14. Lora A, Bai G, Bianchi S, Bolongaro G, Civenti G, Erlicher A, Maresca G, Monzani E, Panetta B, Von Morgen D. The Italian version of HoNOS (Health of the Nation Outcome Scales), a scale for evaluating the outcome and the severity in mental health services [Italian]. Epidemiol Psichiatr Soc. 2001;10(3):198-204.

15. Ruggeri M, Gater R, Bisoffi G, Barbui C, Tansella M. Determinants of subjective quality of life in patients attending community-based mental health services. The SouthVerona Outcome Project 5. Acta Psychiatr Scand. 2002; 105(2):131-40. [PMID: 11939963]

16. Morosini P, Roncone R, Veltro F, Palomba U, Casacchia M. Routine assessment tool in psychiatry: A case of questionnaire of family attitudes and burden. Ital J Psychiatry Behav Sci. 1991;1(1):95-101.

17. Lelliott P. Definition of severe mental illness. In: Charlwood P, Mason A, Goldacre M, Cleary R, Wilkinson E, editors. Health outcomes indicators: Severe mental illness. Report of a working group to the Department of Health. Oxford (England): National Centre for Health Outcomes Development; 1999. p. 87-93.

18. Parabiaghi A, Barbato A, D’Avanzo B, Erlicher A, Lora A. Assessing reliable and clinically significant change on
Health of the Nation Outcome Scales: Method for displaying longitudinal data. Aust N Z J Psychiatry. 2005;39(8): 719-25. [PMID: 16050926]

19. Fitzmaurice GM, Laird NM, Ware JH. Applied longitudinal analysis. Hoboken (NJ): Wiley-Interscience; 2004.

20. Warner R, De Girolamo G, Belelli G, Bologna C, Fioritti A, Rosini G. The quality of life of people with schizophrenia in Boulder, Colorado, and Bologna, Italy. Schizophr Bull. 1998;24(4):559-68. [PMID: 9853789]

21. De Girolamo G, Barbato A, Bracco R, Gaddini A, Miglio R, Morosini P, Norcio B, Picardi A, Rossi E, Rucci P, Santone G, Dell'acqua G; the PROGRES-Acute group. Characteristics and activities of acute psychiatric in-patient facilities: National survey in Italy. Br J Psychiatry. 2007; 191:170-77. [PMID: 17666503]

22. Gaylord V, Lieberman L, Abery B, Lais G, editors. Impact: Feature issue on social inclusion through recreation for persons with disabilities. Minneapolis (Minnesota): University of Minnesota Institute on Community Integration; 2003.

23. Barnett AJ, Van der Pols JC, Dobson AJ. Regression to the mean: What it is and how to deal with it. Int $\mathrm{J}$ Epidemiol. 2005;34(1):215-20. [PMID: 15333621]

24. Bosnack C, Adam L, Haefliger T, Besson J, Conus P. Difficult-to-engage patients: A specific target for time-limited assertive outreach in a Swiss setting. Can J Psychiatry. 2005;50(13):845-50. [PMID: 16483119]

25. Priebe S, Watts J, Chase M, Matanov A. Processes of disengagement and engagement in assertive outreach patients: Qualitative study. Br J Psychiatry. 2005;187:438-43.

[PMID: 16260819]

Submitted for publication February 26, 2007. Accepted in revised form July 9, 2007. 